\title{
Catalytic Steam Reforming of Toluene for Hydrogen Production over Nickel-Cobalt Supported Activated Carbon
}

\author{
Hamdya Sabrina Mohidin Yahya, Nor Aishah Saidina Amin* \\ Chemical Reaction Engineering Group (CREG), School of Chemical \& Energy Engineering, Faculty of Engineering, \\ Universiti Teknologi Malaysia (UTM), Johor Bahru, 81310, MALAYSIA. \\ *Corresponding's author
}

DOI: https://doi.org/10.30880/ijie.2019.11.07.027

Received 16 July 2019; Accepted 20 October 2019; Available online 15 November 2019

\begin{abstract}
Tar formation during biomass gasification is the main obstacle in the sustainable hydrogen $\left(\mathrm{H}_{2}\right)$ production, which increases the processing cost due to clogging of pipes and engines as well as reducing the desired product efficiency. In this present study, catalytic performance of $\mathrm{Ni}$ and/or Co supported on modifiedpalm kernel shell-derived activated carbon (AC) catalysts in steam reforming of toluene (tar model compound) for $\mathrm{H}_{2}$ production was investigated. Experiments were performed to investigate the effect of several factors on toluene conversion $\left(\mathrm{X}_{\text {toluene }}\right)$ and $\mathrm{H}_{2}$ yield $\left(\mathrm{Y}_{\mathrm{H} 2}\right)$, including surface pretreatment using nitric acid to AC support and metal loading content of $\mathrm{Ni}$ and/or Co. The synthesized catalysts were characterized using FTIR, BET, XRD, TGA and FESEM-EDX. The $10 \% \mathrm{Ni}-10 \% \mathrm{Co} / \mathrm{ACN}$ catalyst exhibited the highest $\mathrm{X}_{\text {toluene }}$ and $\mathrm{Y}_{\mathrm{H} 2}$ with $70 \%$ and $69 \%$, respectively, attributed by its improved coke-resistance capability during reaction. This is contributed from the formation of Ni-Co solid solution alloys and homogenous metal distribution due to the increment of surface area, microporous structure and surface functional group after pretreatment. Bimetallic Ni-Co supported on modifiedAC catalyst has high potential as low-cost biomass-derived catalyst in tar removal for hydrogen production.
\end{abstract}

Keywords: Activated carbon, steam reforming, toluene, hydrogen

\section{Introduction}

Global energy supply is almost entirely dependent on fossil fuels such as oil, coal and natural gas [1]. Thus, utilization of non-renewable resources has led to a significant increase of greenhouse gas emission affecting the environment due to climate change. Therefore, reduction of global warming impact has driven the attention towards utilizing renewable source of energy, including biomass [2]. Synthesis gas (syngas), a mixture of primarily carbon monoxide $(\mathrm{CO})$ and hydrogen $\left(\mathrm{H}_{2}\right)$ has been seen as a promising energy source to replace conventional fossil fuelbased energy. Syngas can also be utilized as an alternative to natural gas fuel for power or $\mathrm{H}_{2}$ production. Compared to fossil fuel, biomass has significant advantages such as abundantly available, inexhaustibility, renewability, carbonneutrality and low sulfur content. The syngas can also be used further as a feedstock for the production of hydrocarbon fuels via the Fischer-Tropsch synthesis (FTS) process. However, biomass-based syngas contains high concentration of tars byproducts, which represent a mixture of several aromatic compounds, that prevents the syngas from direct use and requires an effective tar removal approach. It is essential to remove tar content prior to syngas utilization because the inevitable tars-byproduct causes clogging of lines and heat exchangers as well as catalyst deactivation due to coke formation [3]. Tar formation poses as the greatest hurdles of successful implementation of biomass gasification technologies in a commercial scale. Hence, the removal of tar in biomass gasification is highly desirable.

Catalytic steam reforming (SR) of tar is one of the most promising technique because of its high conversion efficiency for hydrogen production [4]. Additionally, catalytic SR of tars is able to increase syngas production where it 
is usually insufficient for FTS (requires about $\mathrm{H}_{2} / \mathrm{CO}=2$ ) and other syngas conversion. However, due to complexity of tar compositions, different model molecules representatives of tar have been used in previous studies such as toluene, benzene, phenol, and naphthalene. Nickel (Ni)-based catalysts are widely used as SR catalyst because of its high activity, low-cost and easy regeneration [5], but tends to suffer from catalyst deactivation during SR of toluene (SRT) caused by coke deposition and metal sintering. Thus, modification of Ni-based catalyst towards promoting higher catalytic performance in SR with more coke-resistant and stable catalyst is still a challenge at present. One of the successful modification techniques in improving the catalytic performances of Ni-based catalyst in steam reforming for hydrogen production is the addition of second metals such as cobalt (Co). Ebshish and coworkers reported that the addition of $\mathrm{Co}$ in $\mathrm{Ni} / \gamma-\mathrm{Al}_{2} \mathrm{O}_{3}$ catalyst exhibited higher catalytic performance with better activity and hydrogen selectivity as compared to $\mathrm{Ni} / \gamma-\mathrm{Al}_{2} \mathrm{O}_{3}$ promoted with $\mathrm{Na}, \mathrm{Fe}$ and $\mathrm{Cu}$ [6]. Bimetallic catalyst has been proven to increase the catalytic efficiency due to synergistic combination of both metals improving stability and resistance from deactivation [7, 8]. Ni and Co metal catalysts are cost effective and makes it as promising candidates for SRT Several studies have reported that bimetallic Ni-Co catalyst produced higher conversion in SRT and other tar model compounds for $\mathrm{H}_{2}$ production with high stability in SR reaction [9-12]. In fact, Co catalyst registered much higher activity than Ni catalysts and has been extensively used in SR of oxygenates (methanol and ethanol) [13]. However, supported metal catalysts possess more advantages in many respects than unsupported metal catalysts [5].

Catalyst support plays an important role for supported metal catalyst to provide a structural framework and stabilizes the active metal species as well as the enhancement of mechanically robustness of the catalyst [14]. In some cases, the support itself provides the new active sites to the system especially those that comprises of both acidic and basic functional groups. The main objective in metal supported catalyst preparation for SRT is to obtain the catalyst in a high dispersion of the catalytically active metal on the surface of support while promoting carbon removal or suppressing its formation. Recent interest in utilizing activated carbon-supported metals catalysts in steam reforming of tar has emerged [15-17]. Activated carbon (AC) exhibits unique properties when it is used as a catalyst support, such as high surface area, stable in both acidic and basic media, as well as possibility of tuning both its textural surface characteristic and surface chemical properties [18, 19]. Catalytic reactivity of AC-based catalyst is driven by the high surface area properties as well as the oxygen-containing functional groups on its surface. Other than that, metal dispersion and metal-carbon interaction also affect catalytic reactivity in SR reaction.

The dispersion of active metal particles is highly influenced by the preparation of support material. Oxidizing pretreatment of AC support using nitric acid, hydrogen peroxide and sulfuric acid is able to improve the surface properties as well as to increase the surface oxygen functional groups. Improving the dispersion of active metal particles on AC support material generally increases the catalytic activity [17]. Catalytic activity test using pretreatedAC supported metal catalyst exhibited higher conversion efficiency as compared to untreated AC catalyst [16, 20, 21]. Thus, the objective of this study is to evaluate the catalytic performance of nickel and/or cobalt supported nitric acidpretreated AC in SRT for hydrogen production. Critical evaluation of catalyst physicochemical properties on activity and stability is expected to elucidate the effectiveness of the synthesized catalyst in SRT and tar removal.

\section{Materials and Methodology}

Raw palm kernel shell-derived activated carbon (AC) (1-5 mm) was purchased from Multi Filter Sdn Bhd (Malaysia). AC was washed with distilled water to remove impurities and oven-dried at $110^{\circ} \mathrm{C}$ overnight. Nitric acid (65\%, Mërck) was used to modify AC support prior metal impregnation step. High purity commercial powder of nickel (II) nitrate hexahydrate $\left(\mathrm{Ni}\left(\mathrm{NO}_{3}\right)_{2} \cdot 6 \mathrm{H}_{2} \mathrm{O}\right)\left(98 \%\right.$, Mërck) and cobalt (II) nitrate hexahydrate $\left(\mathrm{Co}\left(\mathrm{NO}_{3}\right)_{2} .6 \mathrm{H}_{2} \mathrm{O}\right)(98 \%$, Sigma-Aldrich) were used as metal oxide precursor to impregnate AC support. Metal nitrates and analytical toluene (98\%, QRëc) were used as received without further treatment.

\subsection{Catalyst Preparation}

\subsubsection{Pretreatment of AC Support}

Palm kernel shell-derived AC (AC) was used as catalyst support after surface modification. First, raw AC granules was grinded and sieved to obtain particles with diameter $<100 \mu \mathrm{m}$. Nitric acid $\left(\mathrm{HNO}_{3}\right)$ was used as an oxidizing agent for AC surface pretreatment in a liquid phase treatment. In this process, AC particles were dispersed in boiling deionized water and heated for $2 \mathrm{~h}$. AC was filtered and washed for several times to remove ash. The filtered and washed-out $\mathrm{AC}$ was re-dispersed in $400 \mathrm{ml} 10 \mathrm{wt} . \% \mathrm{HNO}_{3}$ aqueous solution and refluxed at $80{ }^{\circ} \mathrm{C}$ for $5 \mathrm{~h}$. Finally, $\mathrm{HNO}_{3}$-pretreated $\mathrm{AC}(\mathrm{ACN})$ sample was filtered and thoroughly washed with distilled water until $\mathrm{pH}=7$. It was then dried in the oven for $12 \mathrm{~h}$ at $110^{\circ} \mathrm{C}$.

\subsubsection{Metal-supported Catalysts Preparation}

The dried AC pretreated by $\mathrm{HNO}_{3}$ as described earlier was used as catalyst support. The synthesis of monometallic and bimetallic $\mathrm{Ni}$ and/or Co supported on $\mathrm{ACN}$ catalysts was carried out via wet impregnation using metal nitrate hexahydrate of $\mathrm{Ni}$ and/or $\mathrm{Co}$ as metal precursor. In this process, $2.5 \mathrm{~g}$ of ACN support was impregnated with 10 wt.\% 
metal loading of $\mathrm{Ni}\left(\mathrm{NO}_{3}\right)_{2} \cdot 6 \mathrm{H}_{2} \mathrm{O}$ and/or $\mathrm{Co}\left(\mathrm{NO}_{3}\right)_{2} \cdot 6 \mathrm{H}_{2} \mathrm{O}$ solution. The ratio between $\mathrm{ACN}$ and metal nitrate solution is maintained at $2.5 \mathrm{~g}: 100 \mathrm{ml}$. The suspension was under magnetic stirring for $5 \mathrm{~h}$ at $60^{\circ} \mathrm{C}$. Resultant slurry was further heated to $110^{\circ} \mathrm{C}$ to evaporate the solution. Subsequently, the obtained solid was oven-dried overnight at $110^{\circ} \mathrm{C}$ and calcined at $500^{\circ} \mathrm{C}$ for $4 \mathrm{~h}$. The final calcined samples were crushed and stored in a desiccator until further use. The synthesized samples are denoted as $10 \% \mathrm{Ni}-\mathrm{ACN}, 10 \% \mathrm{Co}-\mathrm{ACN}$ and $10 \% \mathrm{Ni}-10 \% \mathrm{Co} / \mathrm{ACN}$, accordingly.

\subsection{Catalysts Characterization}

Different techniques were employed for catalysts characterization. To determine the influence of $\mathrm{HNO}_{3}$ pretreated$\mathrm{AC}$ in metal impregnation, Fourier Transform Infrared spectroscopy and multi-point BET-nitrogen $\left(\mathrm{N}_{2}\right)$ adsorptiondesorption was employed to determine surface oxygen functional group and surface properties, respectively. FTIR spectrums were obtained in the range of 4000-400 $\mathrm{cm}^{-1}$ using a Fourier Transform Spectrophotometer with Perkin Elmer Spectrum One instrument (Perkin Elmer, USA). BET surface area analysis was determined through $\mathrm{N}_{2}$-sorption of BET multi-points analysis using a surface area and porosity analyser (Thermo Scientific Surfer Analyzer, Thermo Fisher Scientific, Italy) via $\mathrm{N}_{2}$ adsorption-desorption isotherm collected at $77 \mathrm{~K}$. Subsequently, powder X-ray diffraction analysis of catalysts were conducted to identify crystalline phases of $\mathrm{Ni}$ and Co present in the catalysts. XRD experiments were performed using D5000 Siemens instrument recorded over an angular range $2 \theta$ from $20^{\circ}$ to 90 。 with a scanning rate of $1.2 \circ \mathrm{min}^{-1}$ via $\mathrm{Ni}$-filtered $\mathrm{Cu}-\mathrm{k} \alpha$ radiation $(40 \mathrm{keV}, 40 \mathrm{~mA})$. Thermal behaviour of catalyst samples was also recorded by thermogravimetric analysis (TGA) and differential thermal analysis (DTA) using TGA 8000 system with Pyris Diamond TG/DTA apparatus from Perkin Elmer instruments (Perkin Elmer, USA) under N 2 environment with a ramp rate of $10{ }^{\circ} \mathrm{C}$ min to $900{ }^{\circ} \mathrm{C}$. Field Emission Scanning Electron Microscopy equipped with Energy Dispersive X-ray spectrometer (FESEM-EDX) using Hitachi SU8020 integrated with beam of X-Max ${ }^{\mathrm{N}}$ by Oxford instrument optics (Hitachi High-Technologies Corporation, Japan) was employed to investigate catalysts surface morphology and distribution of $\mathrm{Ni}$ and/or Co metal on the ACN support.

\subsection{Catalytic Activity in Steam Reforming of Toluene}

The experimental setup consists of a preheater, furnace, stainless steel fixed bed reactor, high pressure liquid HPLC pump, syringe pump, a circular cooling unit, a condenser and a gas chromatography (GC) equipped with flame ionization detector (FID) and thermal conductivity detector (TCD) (Fig. 1). The mixed water-toluene liquid feed at a total feed flow rate of $8.25 \mathrm{ml} / \mathrm{min}$ was flowed into the preheater using high-performance metering pump (HPLC) and syringe pump. It was then completely vaporized through the preheater set at $200{ }^{\circ} \mathrm{C}$. $\mathrm{N}_{2}$ was used as carrier gas at controlled rate of $15 \mathrm{ml} / \mathrm{min}$ which was maintained by mass flow controller (Alicat Scientific, USA). The $\mathrm{N}_{2}$-vaporised feed mixture were flowed into a $13 \mathrm{~mm}$ diameter stainless-steel fixed bed reactor loaded with catalyst $(0.3 \mathrm{~g})$ placed in between ceramic wools to ensure fixed position of catalyst. SRT reaction was conducted at steam-to-carbon (S/C) ratio and temperature of 5 and $700{ }^{\circ} \mathrm{C}$, respectively. Effect of stainless-steel reactor and ceramic wool was considered negligible in calculating the catalytic activity and selectivity. The gaseous product was cooled to $10{ }^{\circ} \mathrm{C}$ using a condenser and analyzed online using Agilent GC 6890N equipped with FID (detection of $\mathrm{H}_{2}, \mathrm{CO}_{\text {and }} \mathrm{CO}_{2}$ ), TCD (detection of hydrocarbon) and capillary columns (Agilent, $60 \mathrm{~m} \times 0.32 \mathrm{~mm}$ ID;HP-Plot Q, $40 \mathrm{~m} \times 0.53 \mathrm{~mm}$ ID, 40 $\mu \mathrm{m}$; and Molsieve, $30 \mathrm{~m} \times 0.530 \mathrm{~mm}$ ID, $25 \mu \mathrm{m}$ ). The total flow rate of produced gas was measured using digital flow meter.

Equations (1) to (4) were used to calculate toluene conversion $\left(\mathrm{X}_{\text {toluene }}\right)$, yield of hydrogen $\left(\mathrm{Y}_{\mathrm{H} 2}\right)$ and carboncontaining product $\left(\mathrm{Y}_{\mathrm{i}}\right)$. $\mathrm{Y}_{\mathrm{H} 2}$ was expressed as percentage of actual $\mathrm{H}_{2}$ produced per maximum mole of stoichiometric $\mathrm{H}_{2}$ produced, assuming 1 mole of toluene produced 18 moles of $\mathrm{H}_{2} . \mathrm{F}^{\text {out }}$ and $\mathrm{F}^{\text {in }}$ are output and input molar flow rates, respectively.

$$
\begin{aligned}
X_{\text {toluene }}(\%) & =\frac{F_{C O}^{\text {out }}+F_{\mathrm{CO}_{2}}^{\text {out }}+F_{\mathrm{CH}_{4}}^{\text {out }}}{7 \times F_{\text {toluene }}^{\text {in }}} \times 100 \\
Y_{H_{2}}(\%) & =\frac{F_{\mathrm{H}_{2}}^{\text {out }}}{18 \times F_{\text {Toluene }}^{\text {in }}} \times 100 \\
Y_{i}(\%) & =\frac{\# C \times F_{i}^{\text {out }}}{7 \times F_{\text {toluene }}^{\text {in }}} \times 100
\end{aligned}
$$

Molar flow rates of $\mathrm{H}_{2}, \mathrm{CO}, \mathrm{CO}_{2}, \mathrm{CH}_{4}$ (products) and toluene (reactant) at outlet and inlet are specified in mol/h unit and denoted as $F_{\mathrm{H}_{2}}^{\text {out }}, F_{\mathrm{CO}}^{\text {out }}, F_{\mathrm{CO}_{2}}^{\text {out }}, F_{\mathrm{CH}_{4}}^{\text {out }}$ and $F_{\text {toluene }}^{\text {in }}$, accordingly. Product selectivity is the molar percentage of products obtained, excluding unconverted toluene, water and $\mathrm{N}_{2}$ (carrier gas). 


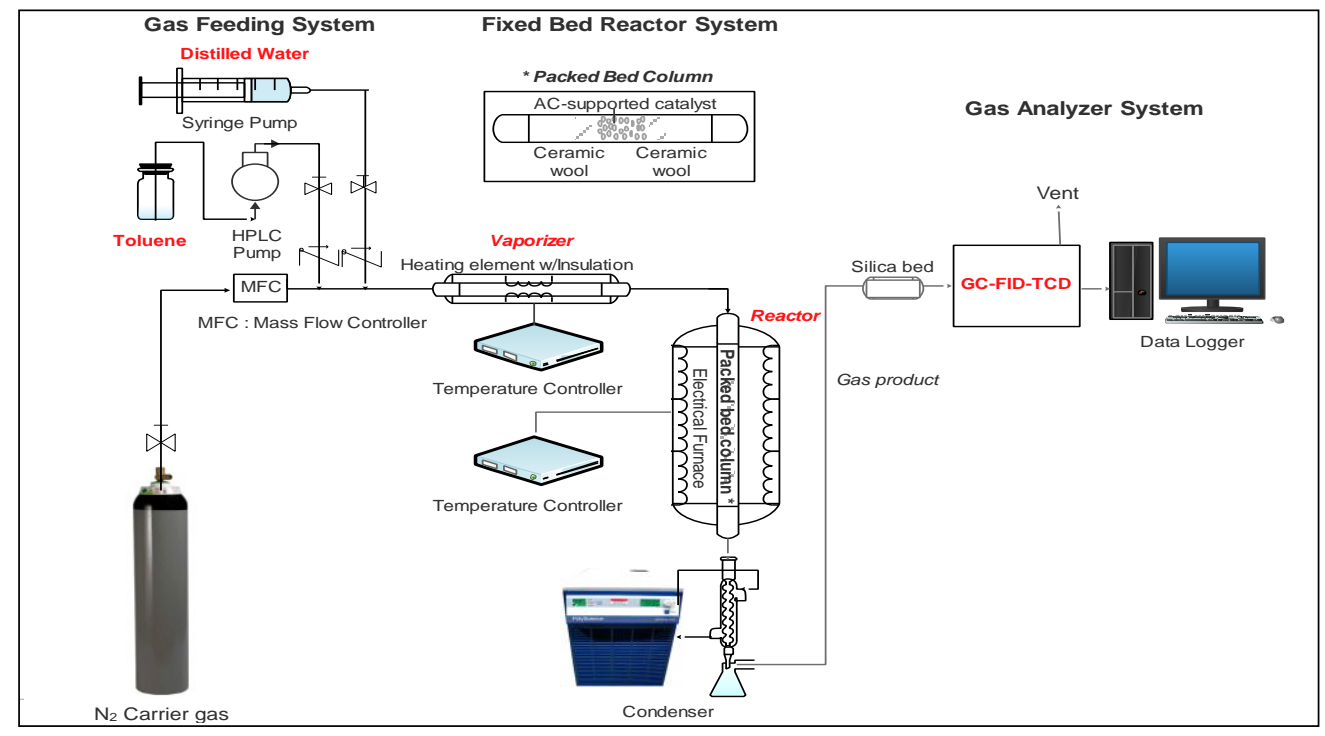

Fig. 1 Schematic layout of experimental setup of catalytic SRT for hydrogen production.

\section{Results and Discussions}

\subsection{Catalyst Characterization}

The surface oxygenated functional groups (SOFG) present in the untreated AC, ACN and the synthesized catalyst samples $(\mathrm{Ni} / \mathrm{ACN}, \mathrm{Co} / \mathrm{ACN}$ and $\mathrm{NiCo} / \mathrm{ACN})$ are determined by FTIR analysis. The resultant FTIR spectra (Fig. 2a) exhibit a broad band at $3440 \mathrm{~cm}^{-1}$ attributed by hydroxyl $\left(\mathrm{OH}^{-}\right)$groups associated to moisture present in the five catalyst samples [22]. Other prominent peaks are observed in 400-1700 $\mathrm{cm}^{-1}$ region. The band peak at $1717 \mathrm{~cm}^{-1}$ are attributed by $\mathrm{C}=\mathrm{O}$ (carboxyl and carboxylate group) which has increased upon $\mathrm{HNO}_{3}$ pretreatment [23]. The presence of these functional groups will increase the hydrophilicity properties of the carbon materials and assists the adsorption of metal ions onto the surface of AC support more homogeneously [20]. However, decreasing peak at $\sim 1425 \mathrm{~cm}^{-1}$ of $\mathrm{ACN}$ catalyst compared to $\mathrm{AC}$ indicates $\mathrm{C}-\mathrm{O}$ of quinonic group reduced after pretreatment suggesting the corrosive nature of nitric acid had caused the removal of this group [24, 25]. Furthermore, the possible presence of Ni- and/or CoACN complex [23] with band peak of Co-O and Ni-O at $\sim 669 \mathrm{~cm}^{-1}, 568 \mathrm{~cm}^{-1}$ and $\sim 46 \mathrm{~cm}^{-1}$, respectively, which are not present in AC and ACN samples indicate the tensile vibration of Ni-O and Co-O bands [26]. These results confirm the successful incorporation of $\mathrm{Ni}^{2+}$ and/or $\mathrm{Co}^{2+}$ cations onto the surface of ACN supported catalysts.

Based on $\mathrm{N}_{2}$ adsorption-desorption isotherm analysis (Fig. 2b), textural properties of synthesized catalysts such as BET surface area $\left(\mathrm{S}_{\mathrm{BET}}\right)$, micropore surface area $\left(\mathrm{S}_{\text {micro }}\right)$, pore volume $\left(\mathrm{V}_{\mathrm{t}}\right)$ and average pore diameter are summarized in Table 1. The isotherms for AC, ACN and Ni-Co/ACN catalysts depict hybrid characteristic of Type I and IV according to the IUPAC classification, indicating micropores and mesoporous material [27]. The uptake for ACN sample higher than $\mathrm{AC}$ infers that amount of micropores increased after the $\mathrm{HNO}_{3}$ pretreatment. The surface pretreated ACN gives significant increment of $\mathrm{S}_{\mathrm{BET}}, \mathrm{S}_{\text {micro }}$ and $\mathrm{V}_{\mathrm{t}}$ amount compared to AC. The addition of $10 \mathrm{wt} . \% \mathrm{Ni}$ and Co loading gives smaller $S_{B E T}, S_{\text {micro }}$ and $V_{t}$ compared to $A C$ and $A C N$ samples. It could be attributed to the successful metal impregnation and partial pore filling of Ni-Co/ACN [23]. This can be confirmed further by FESEM-EDX through metal distribution mapping of $\mathrm{Ni}-\mathrm{Co} / \mathrm{ACN}$ catalyst.

Table 1 Surface properties of the prepared catalysts.

\begin{tabular}{lllll}
\hline Catalysts & BET surface area, & $\begin{array}{l}\text { Micropore surface } \\
\text { area, } \mathrm{S}_{\text {micro }}\left(\mathrm{m}^{2} \mathrm{~g}^{-1}\right)\end{array}$ & $\begin{array}{l}\text { Pore volume, } \\
\mathrm{V}_{\mathrm{t}}\left(\mathrm{cm}^{3} \mathrm{~g}^{-1}\right)\end{array}$ & $\begin{array}{l}\text { Average pore } \\
\text { diameter }(\mathrm{nm})\end{array}$ \\
\hline Untreated AC & 684.29 & 632.86 & 0.32 & 2.12 \\
$\mathrm{ACN}$ & 850.03 & 775.61 & 0.50 & 1.87 \\
$10 \% \mathrm{Ni}-10 \% \mathrm{Co} / \mathrm{ACN}$ & 462.66 & 397.77 & 0.28 & 2.40 \\
\hline
\end{tabular}


a)

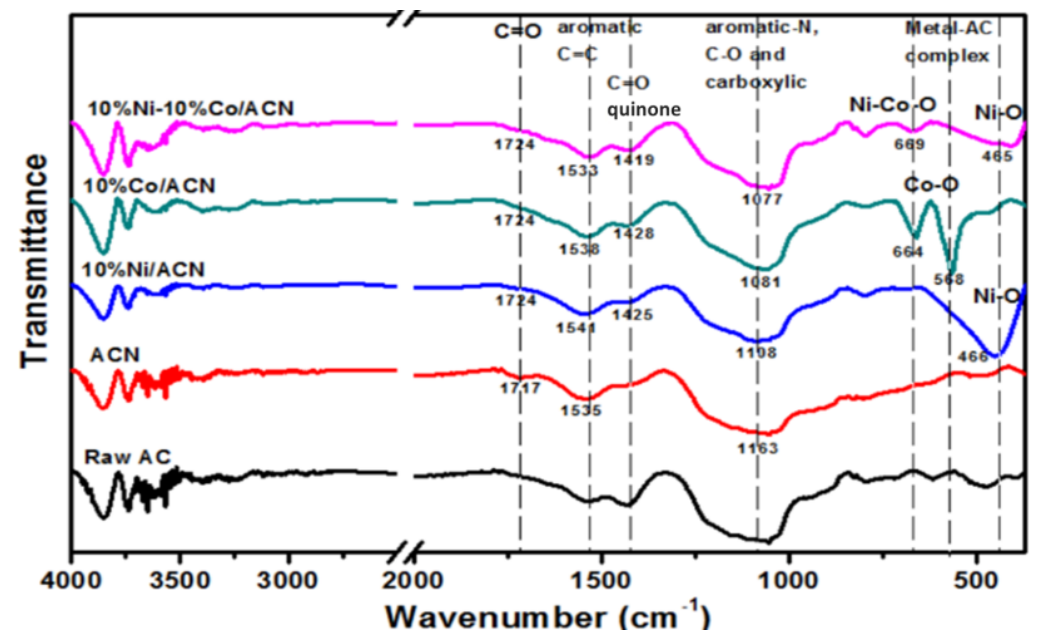

b)

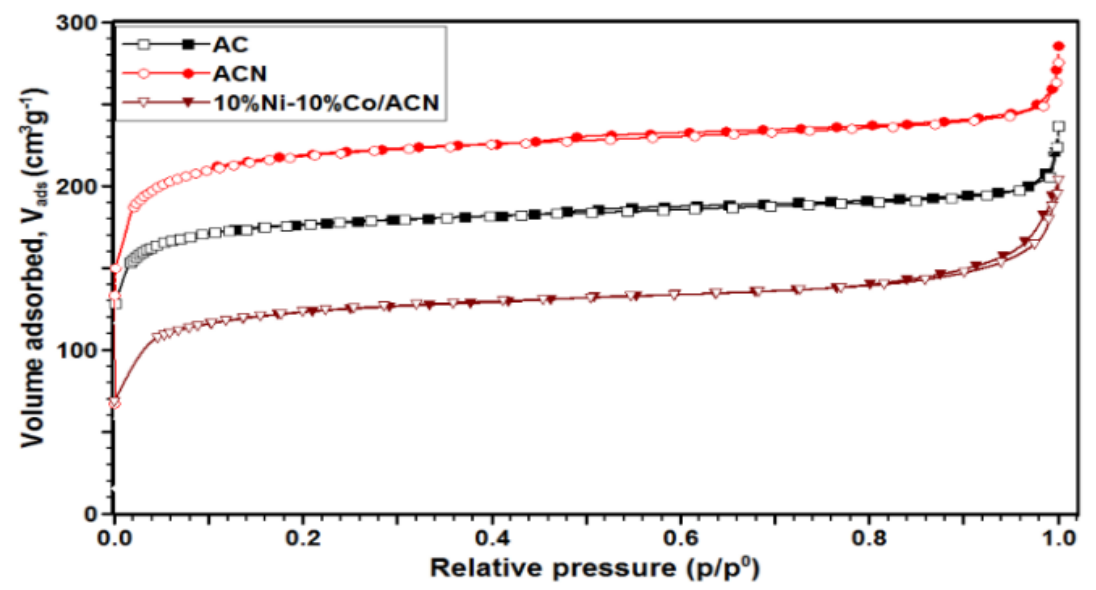

Fig. 2 (a) FTIR spectrums of AC, ACN, Ni/ACN, Ni/ACN and Ni-Co/ACN catalysts; and (b) $\mathrm{N}_{2}$-adsorption desorption isotherm of $\mathrm{AC}, \mathrm{ACN}$ and $\mathrm{Ni}-\mathrm{Co} / \mathrm{ACN}$ catalysts.

Powder X-ray Diffraction (XRD) analysis was employed to determine crystallite phase and structure of Ni-Co supported on ACN catalyst. Fig. 3a shows the effect of XRD pattern of raw AC and bimetallic Ni-Co supported ACN catalysts. AC sample displays broad diffraction peaks at $2 \theta$ angles of $25.3^{\circ}(002)$ and $43.62^{\circ}(101)$, which can be assigned as amorphous and graphene or graphite carbon (ICDD PDF-2\# 01-041-1487). Saleh and Danmaliki also found similar XRD patterns of AC without pretreatment [28]. Slight decrease of these peaks upon impregnation were observed for $10 \% \mathrm{Ni}-10 \% \mathrm{Co} / \mathrm{ACN}$. Similar findings, reported by Cui et. Al., claimed the crystallinity of AC decreased slightly upon metal impregnation [29]. Bimetallic Ni-Co supported ACN depict diffraction patterns of nickel oxide and/or cobalt oxide at $2 \theta$ angles of $31.18^{\circ}, 36.75^{\circ}, 42.83^{\circ}, 43.45^{\circ}, 59.10^{\circ}, 62.23^{\circ}, 64.50^{\circ}, 74.60^{\circ}$ and $78.43^{\circ}$ which is consistent with library XRD of NiO (ICDD PDF-2\# 01-078-4374), $\mathrm{CoO}$ (ICDD PDF-2\# 01-070-2855) and $\mathrm{Co}_{3} \mathrm{O}_{4}$ (ICDD PDF-2\# 03-065-3103). This confirms the active phases of NiO, $\mathrm{CoO}$ and $\mathrm{Co}_{3} \mathrm{O}_{4}$ are present in Ni-Co supported ACN catalyst as listed in Table 2 corresponding to the facets of each compound [30,31]. Furthermore, the presence of $\mathrm{NiO}$ and $\mathrm{CoO}$ or $\mathrm{Co}_{3} \mathrm{O}_{4}$ phase in bimetallic supported catalysts also affects the diffraction peaks where the diffraction peaks are seen to be shifted slightly to lower value of $2 \theta$ for carbon [28, 32]. These may be contributed by the formation of interacted species between $\mathrm{Ni}$ and $\mathrm{Co}$ with $\mathrm{ACN}$ support [31]. These findings are in agreement with the data reported in the ICDD PDF-2 card and those reported in previous studies.

Carbon deposition is one of the major limitations in SR reaction. This is because it has tendency to block active metal sites leading catalyst deactivation. Thermogravimetric analysis (TGA) and differential thermogravimetric analysis (DTA) were employed to provides insights of the amount and nature of deposited carbon over spent catalysts of $10 \% \mathrm{Ni} / \mathrm{ACN}, 10 \% \mathrm{Co} / \mathrm{ACN}$ and $10 \% \mathrm{Ni}-10 \% \mathrm{Co} / \mathrm{ACN}$ after $5 \mathrm{~h}$ in SRT reaction from 20 to $900{ }^{\circ} \mathrm{C}$, as shown in Fig. $3 \mathrm{~b}$. Initial decomposition at temperature between $20-80{ }^{\circ} \mathrm{C}$ is associated with the release of moisture and physisorbed water from the surface of catalysts. The weight loss reached up to $10 \%$ for both $10 \% \mathrm{Ni} / \mathrm{ACN}$ and $10 \% \mathrm{Co} / \mathrm{ACN}$, whereas $10 \% \mathrm{Ni}-10 \% \mathrm{Co} / \mathrm{ACN}$ only have slight weight loss of moisture in this region. Subsequently, all catalysts conferred profound weight losses starting at $530{ }^{\circ} \mathrm{C}$ until $550{ }^{\circ} \mathrm{C}$ attributed by the total oxidation of carbon to $\mathrm{CO}_{2}$. High temperature of oxidation indicates the decomposition of carbon nanotube is around $450-550{ }^{\circ} \mathrm{C}[33,34]$. The amount of coke formation was observed to be decreasing for $10 \% \mathrm{Co} / \mathrm{ACN}, 10 \% \mathrm{Ni} / \mathrm{ACN}$ and $10 \% \mathrm{Ni}-10 \% \mathrm{Co} / \mathrm{ACN}$ with $30 \mathrm{wt} . \%$, $15 \mathrm{wt} . \%$ and $8 \mathrm{wt} . \%$, respectively. The weight decrease occurred above $550{ }^{\circ} \mathrm{C}$ for all catalysts owing to the formation 
of graphite carbon, as observed by Quitete et al [35]. The final weight loss of catalysts occurred at $900{ }^{\circ} \mathrm{C}$ was established in the following order $10 \% \mathrm{Ni}-10 \% \mathrm{Co} / \mathrm{ACN}<10 \% \mathrm{Ni} / \mathrm{ACN}<10 \% \mathrm{Co} / \mathrm{ACN}$ with $20 \%, 24 \%$ and $45 \%$, respectively. This suggested the relative resistance of carbon formation on the Ni-Co/ACN catalyst. The synergetic combination of active metal Ni-Co alloys onto support had successfully eliminated significant amount of inert or graphitic carbon.
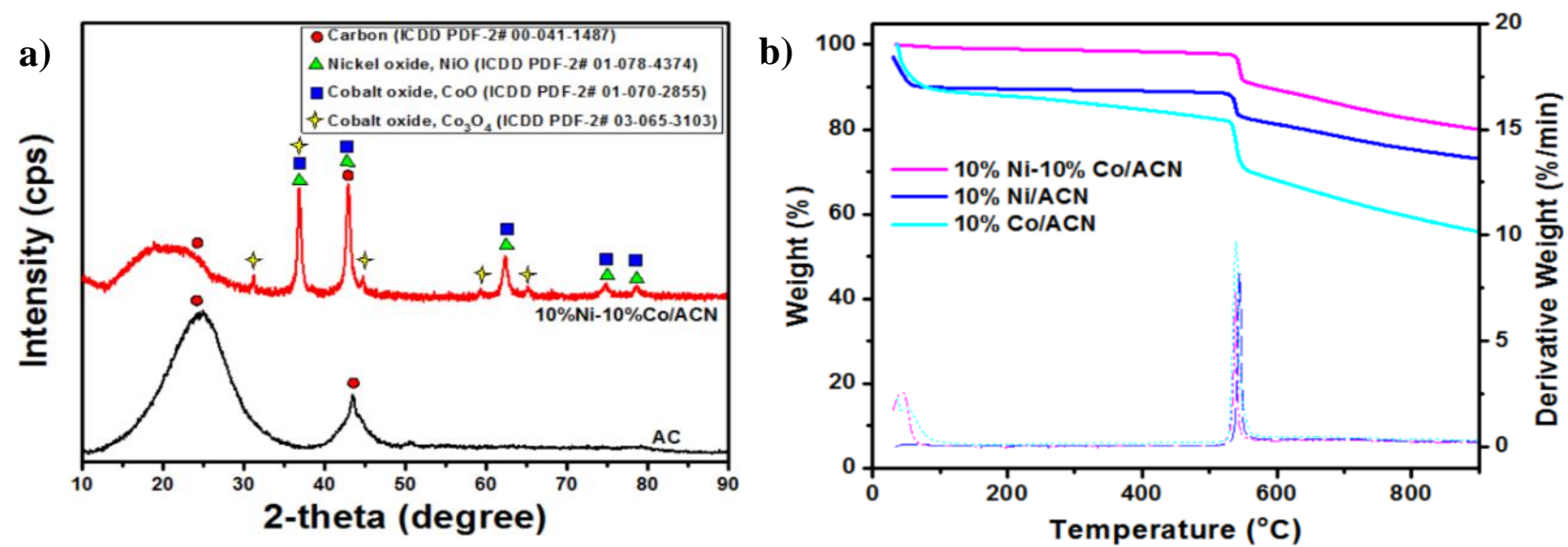

Fig. 3 (a) XRD patterns of $\mathrm{AC}$ and $10 \% \mathrm{Ni}-10 \% \mathrm{Co} / \mathrm{ACN}$; and (b) TGA/DTA profile of spent $10 \% \mathrm{Ni} / \mathrm{ACN}, 10 \% \mathrm{Co} / \mathrm{ACN}$ and $10 \% \mathrm{Ni}-10 \% \mathrm{Co} / \mathrm{ACN}$ catalysts after $5 \mathrm{~h}$ in SRT.

Table 2 XRD analysis of the $10 \% \mathrm{Ni}-10 \% \mathrm{Co} / \mathrm{ACN}$ catalyst.

\begin{tabular}{llll}
\hline & $2 \theta($ degree $)$ & hkl indices & ICDD (PDF-2) \\
\hline $\mathrm{AC}$ & 25.30 & 002 & $01-075-2078$ \\
$\mathrm{NiO}$ & 43.62 & 101 & \\
& 36.9 & 101 & \\
& 42.93 & 012 & \\
& 62.43 & 110 & \\
& 75.04 & 113 & $01-070-2855$ \\
$\mathrm{CoO}$ & 78.91 & 202 & \\
& 36.9 & 111 & \\
& 42.93 & 200 & \\
& 62.43 & 331 & $03-065-3103$ \\
$\mathrm{Co}_{3} \mathrm{O}_{4}$ & 75.04 & 220 & \\
& 78.91 & 311 & \\
& 36.9 & 311 & \\
\hline
\end{tabular}

FESEM-EDX analysis was used to investigate the morphology and active metal distribution on the surface of catalyst support. The morphology of untreated AC, ACN and the active metal Ni-Co loaded on ACN catalysts with different magnification scales were obtained and presented in Fig. 4. The ACN (Fig. 4b) shows increase of pore formation after the surface treatment with $\mathrm{HNO}_{3}$ compared to $\mathrm{AC}$ (Fig. 4a) as confirmed by the BET analysis. The $10 \% \mathrm{Ni}-10 \% \mathrm{Co} / \mathrm{ACN}$ catalyst (Fig. $4 \mathrm{c}-\mathrm{f}$ ) revealed that the metal particles in the catalyst samples with irregular shapes. Partial pore blockage could have occurred due to the deposition of active metals on the surface and into the pores of the support [23]. The distribution of $\mathrm{Ni}$ and $\mathrm{Co}$ metal on the support are demonstrated with cyan and purple dots as depicted in Fig. 4g. Both metal-impregnated catalysts displayed uniform distribution of $\mathrm{Ni}$ and $\mathrm{Co}$ on the surface of AC support inferring the effectiveness of nitric acid pretreatment method for AC support prior to metal impregnation leading to uniform metal dispersion on the support. However, it is also observed upon 25000-40000x magnification that micropores are still partially vacant. Table 3 indicates the weight percent of $\mathrm{Ni}$ and $\mathrm{Co}$ on ACN support of the Ni$\mathrm{Co} / \mathrm{ACN}$ which almost similar to the desired metal loading. 


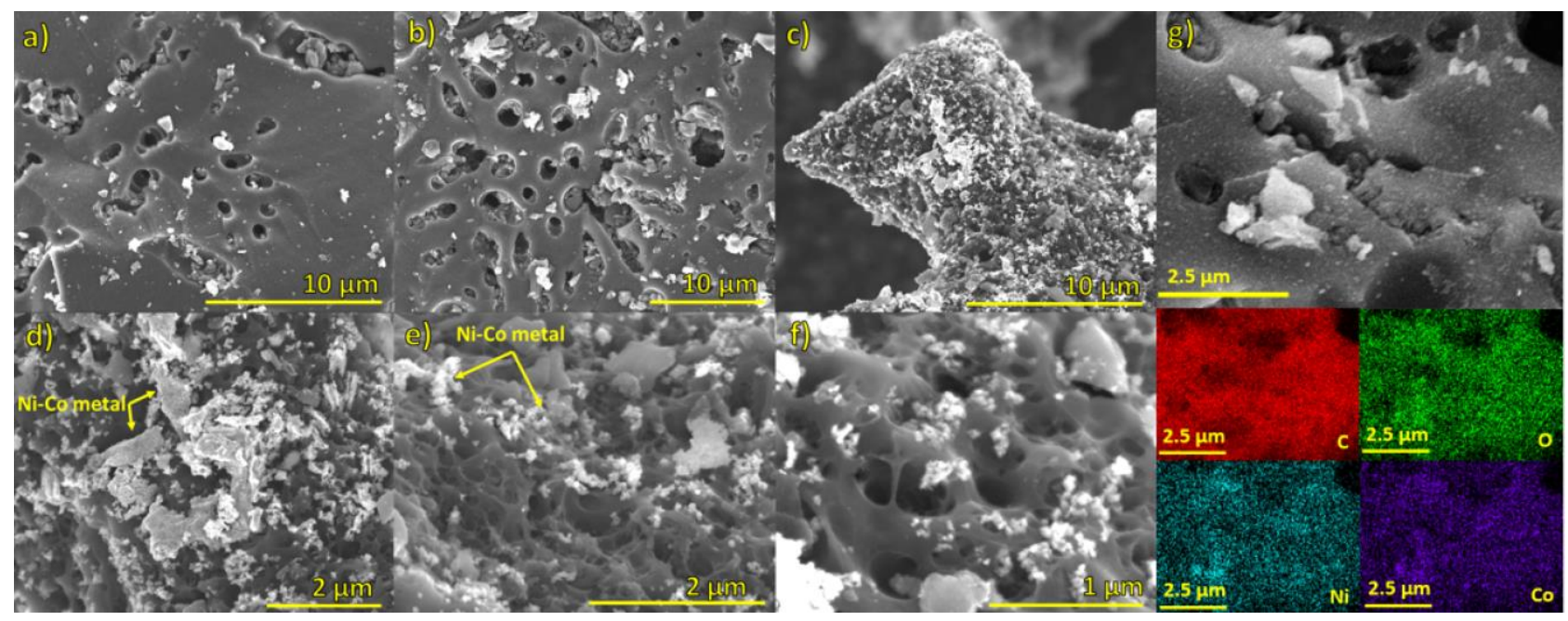

Fig. 4 FESEM images for (a) untreated AC at 5000x; (b) ACN at 5000x; (c) $10 \% \mathrm{Ni}-10 \% \mathrm{Co} / \mathrm{ACN}$ at $5000 \mathrm{x}$; (d) $10 \% \mathrm{Ni}-10 \% \mathrm{Co} / \mathrm{ACN}$ at $15000 \mathrm{x}$; (e) $10 \% \mathrm{Ni}-10 \% \mathrm{Co} / \mathrm{ACN}$ at $25000 \mathrm{x}$; (f) $10 \% \mathrm{Ni}-10 \% \mathrm{Co} / \mathrm{ACN}$ at $40000 \mathrm{x}$; and (g) EDX mapping for $10 \% \mathrm{Ni}-10 \% \mathrm{Co} / \mathrm{ACN}$ catalyst.

Table 3 The loading of $\mathrm{Ni}$ and $\mathrm{Co}$ on the $\mathrm{ACN}$ for $10 \% \mathrm{Ni}-10 \% \mathrm{Co} / \mathrm{ACN}$ catalyst.

\begin{tabular}{lllcl}
\hline Catalyst & \multicolumn{3}{c}{$10 \% \mathrm{Ni}-10 \% \mathrm{Co} / \mathrm{ACN}$} \\
\hline Elements & $\mathrm{O}$ & $\mathrm{C}$ & $\mathrm{Ni}$ & $\mathrm{Co}$ \\
Weight $\%$ & 63.8 & 15.6 & 10.9 & 9.8 \\
\hline
\end{tabular}

\subsection{Catalytic Activity in Steam Reforming of Toluene}

Catalytic activities of homogenous (no catalyst), untreated $\mathrm{AC}, \mathrm{Ni} / \mathrm{ACN}, \mathrm{Co} / \mathrm{ACN}$ and $\mathrm{Ni}-\mathrm{Co} / \mathrm{ACN}$ were evaluated in SRT for hydrogen production during $5 \mathrm{~h}$ of testing time. The hydrogen yield $\left(\mathrm{Y}_{\mathrm{H} 2}\right)$, carbon-containing product yield $\left(\mathrm{Y}_{\mathrm{i}}\right)$ and toluene conversion $\left(\mathrm{X}_{\text {toluene }}\right)$ into gaseous products were evaluated for all catalysts. As depicted in Fig. 5a and $5 \mathrm{~b}$, increasing $\mathrm{X}_{\text {toluene }}$ and $\mathrm{Y}_{\mathrm{H} 2}$ were observed in SRT with the addition of $10 \% \mathrm{Co}, 10 \% \mathrm{Ni}$ and $10 \% \mathrm{Ni}-10 \% \mathrm{Co}$. The catalyst with $10 \% \mathrm{Ni}-10 \%$ Co exhibited the best catalytic performance: the $\mathrm{X}_{\text {toluene }}$ and $\mathrm{Y}_{\mathrm{H} 2}$ was obtained at $70 \%$ and $69 \%$, respectively. Excellent performance of bimetallic $10 \% \mathrm{Ni}-10 \% \mathrm{Co} / \mathrm{ACN}$ catalyst is attributed by the synergistic combination of Ni-Co and high metal dispersion on the AC-modified catalyst support, as proven by the XRD pattern and FESEM-EDX images. High dispersion of active metal particles is contributed by the enhancement of SOFG based on the FTIR spectra which then promotes the homogenous active metal distribution. Furthermore, higher coke-resistant property is registered through the TGA evaluation with the lowest amount of coke deposited on used of $10 \% \mathrm{Ni}$ $10 \% \mathrm{Co} / \mathrm{ACN}$ catalyst compared to the other catalysts. It has been reported that bimetallic Ni-Co catalysts performed well in SR reactions of coal tar [36], toluene [37], and phenol [10]. In addition, $\mathrm{Y}_{\mathrm{CO} 2}$ for $10 \% \mathrm{Ni} / \mathrm{ACN}$ is significantly lower as compared to $10 \% \mathrm{Ni}-10 \% \mathrm{Co} / \mathrm{ACN}$ at $19 \%$ and $42 \%$, respectively. This may be due to lower active metal sites on $10 \% \mathrm{Ni} / \mathrm{ACN}$ compared to $10 \% \mathrm{Ni}-10 \% \mathrm{Co} / \mathrm{ACN}$. Fig. $5 \mathrm{c}$ and $5 \mathrm{~d}$ depict the catalytic activities of $\mathrm{Y}_{\mathrm{H} 2}$ and $\mathrm{X}_{\text {toluene }}$, respectively, as a function of time on stream for the catalysts. Increasing trend of $\mathrm{Y}_{\mathrm{H} 2}$ and $\mathrm{X}_{\text {toluene }}$ are observed for $10 \% \mathrm{Ni}-10 \% \mathrm{Co} / \mathrm{ACN}$. Meanwhile, $\mathrm{Y}_{\mathrm{H} 2}$ over $10 \% \mathrm{Ni} / \mathrm{ACN}$ reduced significantly after $3 \mathrm{~h}$ of reaction. This phenomenon is expected as Ni catalyst commonly undergoes significant deactivation in SRT owing to carbon deposition [38, 39], whereas, low catalytic activities or almost no activities are observed for homogenous, $\mathrm{AC}$ and $10 \% \mathrm{Co} / \mathrm{ACN}$. The deactivation behavior of $\mathrm{Co}$ catalyst in $\mathrm{CO}_{2}$ reforming of toluene is also reported previously by Bao et al due to the sintering effect of metallic Co particles, which depend on the amount of Co loading amount [40]. However, the addition of Co as a metal promoter in bimetallic supported catalyst has shown good results in SR reactions due to the strong interaction between $\mathrm{Ni}$ and $\mathrm{Co}$ alloy that enhances the carbon resistant property [37]. 

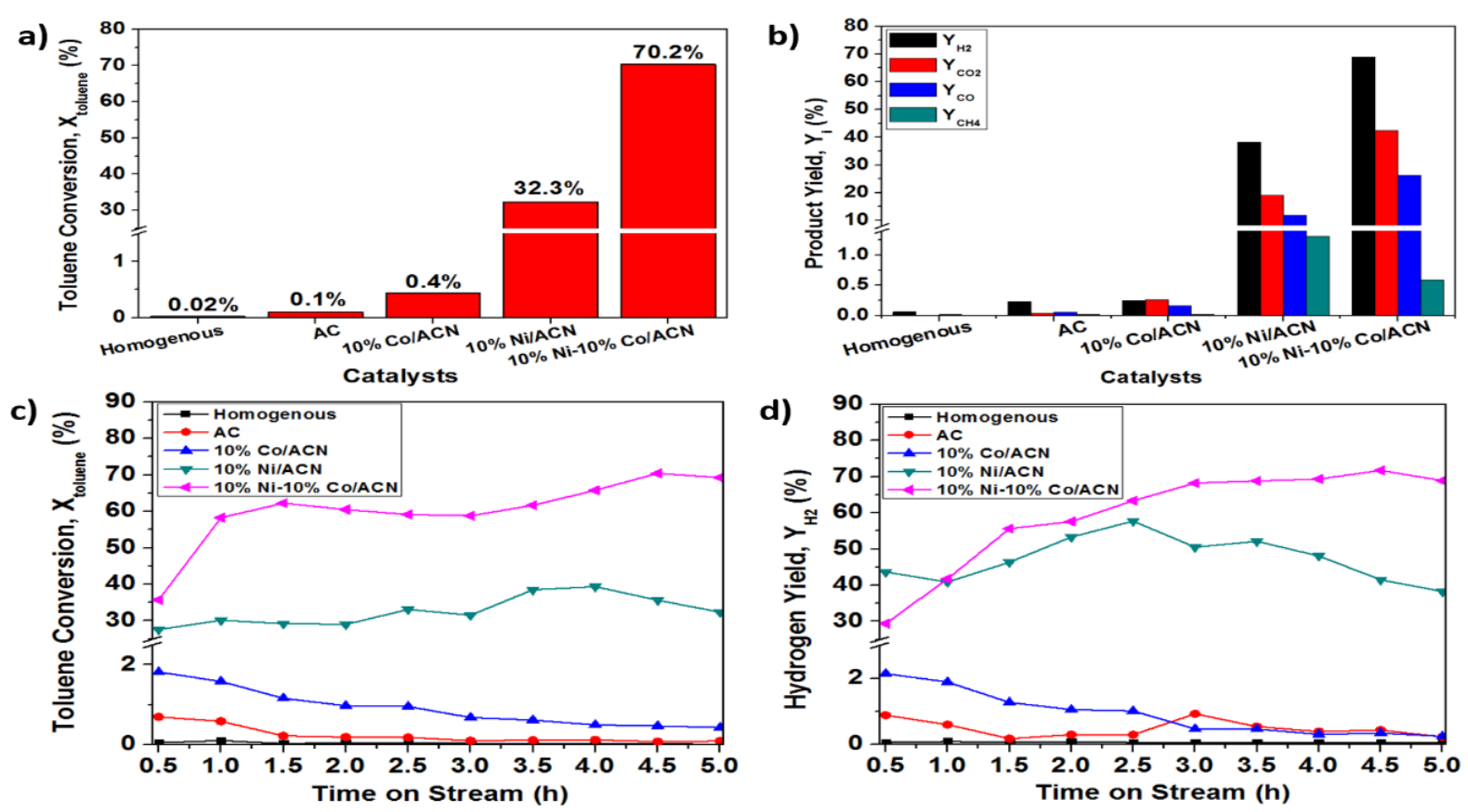

Fig. 5 Catalytic SRT for homogenous, AC, $10 \% \mathrm{Co} / \mathrm{ACN}, 10 \% \mathrm{Ni} / \mathrm{ACN}$ and $10 \% \mathrm{Ni}-10 \% \mathrm{Co} / \mathrm{ACN}$ after $5 \mathrm{~h}$ of (a) toluene conversion; (b) product yield; (c) toluene conversion over time on stream; and (d) hydrogen yield over time on stream.

The main reactions involved in this study are the reaction of SRT (Equation 4-5) and water gas shift (WGS) (Equation 6) [38]. The mechanism initiated by the adsorption of the toluene onto the surface of metal particles followed by toluene dealkylation to benzene and methane (Equation 7). Methane either reacts immediately with water producing $\mathrm{H}_{2}$ and $\mathrm{CO}$ (Equation 8), or further dehydrogenates to $\mathrm{CH}_{\mathrm{x}}$ species and carbon. Higher formation of $\mathrm{CO}_{2}$ compared to $\mathrm{CO}$ over $10 \% \mathrm{Ni}-10 \% \mathrm{Co} / \mathrm{ACN}$ is mainly attributed to the enhanced WGS side reaction that accompanied the SRT reaction. The WGS reactions consume $\mathrm{CO}$ and produces more $\mathrm{H}_{2}$ and $\mathrm{CO}_{2}$, leading to the higher $\mathrm{H}_{2} / \mathrm{CO}$ ratio. Formation of carbon may be the main contributor of the loss of catalytic activity in SRT owing to the Boudouard reaction (Equation 9). The amount of carbon deposited on the spent catalyst obtained from TGA results reveal that higher carbon formation leads to the degradation of catalytic activity. Castro et al reported that increased amount of carbon formation was contributed by the increased acid sites density of catalysts [41, 42]. The main route of carbon deposition on the surface of catalyst could be attributed to oligomerization of toluene on the acidic sites of catalyst support [43].

Steam reforming of toluene

$$
\begin{aligned}
& \mathrm{C}_{7} \mathrm{H}_{8}+14 \mathrm{H}_{2} \mathrm{O} \rightarrow 7 \mathrm{CO}_{2}+18 \mathrm{H}_{2} \quad{ }_{\Delta} \mathrm{H}_{700^{\circ} \mathrm{C}}=680 \mathrm{~kJ} / \mathrm{mol} \\
& \mathrm{C}_{7} \mathrm{H}_{8}+7 \mathrm{H}_{2} \mathrm{O} \rightarrow 7 \mathrm{CO}+11 \mathrm{H}_{2} \quad{ }_{\Delta} \mathrm{H}_{700^{\circ} \mathrm{C}}=925 \mathrm{~kJ} / \mathrm{mol} \\
& \mathrm{CO}+\mathrm{H}_{2} \mathrm{O} \rightleftharpoons \mathrm{CO}_{2}+\mathrm{H}_{2} \quad{ }_{\Delta} \mathrm{H}_{700^{\circ} \mathrm{C}}=-35 \mathrm{~kJ} / \mathrm{mol} \\
& \mathrm{C}_{7} \mathrm{H}_{8}+\mathrm{H}_{2} \rightarrow \mathrm{C}_{6} \mathrm{H}_{6}+\mathrm{CH}_{4} \\
& \mathrm{CH}_{4}+\mathrm{H}_{2} \mathrm{O} \rightarrow \mathrm{CO}+3 \mathrm{H}_{2} \\
& \mathrm{C}+\mathrm{CO}_{2} \rightleftharpoons 2 \mathrm{CO}
\end{aligned}
$$

Water gas shift

Hydrodealkylation:

\section{Conclusion}

The modified AC-supported $\mathrm{Ni}$ and/or Co catalyst were prepared and tested in steam reforming of toluene as biomass tar model compound. The optimum preparation conditions for the AC-supported catalyst are $10 \mathrm{wt} \% \mathrm{of} \mathrm{Ni}$ and $\mathrm{Co}$ loading supported on the $\mathrm{HNO}_{3}$-preteated $\mathrm{AC}$ as catalyst support. The $10 \% \mathrm{Ni}-10 \% \mathrm{Co} / \mathrm{ACN}$ catalyst composition exhibits the best catalytic performance in SRT with the highest catalytic activity at $72 \%$ toluene conversion $\left(\mathrm{X}_{\text {toluene }}\right)$ and $62 \%$ hydrogen yield $\left(\mathrm{Y}_{\mathrm{H} 2}\right)$ obtained after 5 h. Surface modification of AC support using nitric acid has enhanced the impregnation of active bimetals to highly disperse $\mathrm{Ni}$ and Co onto the AC surface. The high surface area, microporous structure, enhancement of SOFG and synergistic combination of Ni-Co alloy formation on 
the surface of ACN support serve as important roles in the improvement of the catalytic activity. These enhancement leads to the coke-resistance capability of the $10 \% \mathrm{Ni}-10 \% \mathrm{Co} / \mathrm{ACN}$ catalyst where the deposited coke amount reduces significantly compared to the other catalysts. Thus, the high performance of $10 \% \mathrm{Ni} 10 \% \mathrm{Co} / \mathrm{ACN}$ catalyst demonstrates its potential as a biomass-based catalyst in tar removal for hydrogen production.

\section{Acknowledgement}

This research is supported by Tier 1 Research University Grant Scheme of Universiti Teknologi Malaysia (17H09). Also, the assistance from University Laboratory Management Unit (UPMU) and Analytical Lab in School of Chemical and Energy Engineering, Faculty of Engineering, Universiti Teknologi Malaysia are highly acknowledged.

\section{References}

[1] British Petroleum (2017). BP Energy Outlook 2017 Edition, 1-104.

[2] Baykara S. Z. (2018). Hydrogen: A brief overview on its sources, production and environmental impact. International Journal of Hydrogen Energy, 43, 10605-10614.

[3] Rios M. L. V., González A. M., Lora E. E. S., Olmo O. A. A. d. (2018). Reduction of tar generated during biomass gasification: A review. Biomass and Bioenergy, 108, 345-370.

[4] Guan G., Kaewpanha M., Hao X., Abudula A. (2016). Catalytic steam reforming of biomass tar: Prospects and challenges. Renewable and Sustainable Energy Reviews, 58, 450-461.

[5] Li D., Tamura M., Nakagawa Y., Tomishige K. (2015). Metal catalysts for steam reforming of tar derived from the gasification of lignocellulosic biomass. Bioresource Technology, 178, 53-64.

[6] Ebshish A., Yaakob Z., Narayanan B., Bshish A., Daud W. R. W. (2011). The activity of Ni-based catalysts on steam reforming of glycerol for hydrogen production. International Journal of Integrated Engineering, 3, 5-8.

[7] Bizkarra K., Bermudez J. M., Arcelus-Arrillaga P., Barrio V. L., Cambra J. F., Millan M. (2018). Nickel based monometallic and bimetallic catalysts for synthetic and real bio-oil steam reforming. International Journal of Hydrogen Energy, 43, 11706-11718.

[8] Wang L., Li D., Koike M., Watanabe H., Xu Y., Nakagawa Y., Tomishige K. (2013). Catalytic performance and characterization of $\mathrm{Ni}-\mathrm{Co}$ catalysts for the steam reforming of biomass tar to synthesis gas. Fuel, 112, 654-661.

[9] Gai C., Zhang F., Yang T., Liu Z., Jiao W., Peng N., Liu T., Lang Q., Xia Y. (2018). Hydrochar supported bimetallic $\mathrm{Ni}-\mathrm{Fe}$ nanocatalysts with tailored composition, size and shape for improved biomass steam reforming performance. Green Chemistry, 20, 2788-2800.

[10] Nabgan W., Tuan Abdullah T. A., Mat R., Nabgan B., Triwahyono S., Ripin A. (2016). Hydrogen production from catalytic steam reforming of phenol with bimetallic nickel-cobalt catalyst on various supports. Applied Catalysis A: General, 527, 161-170.

[11] Heo D. H., Lee R., Hwang J. H., Sohn J. M. (2016). The effect of addition of Ca, K and Mn over Ni-based catalyst on steam reforming of toluene as model tar compound. Catalysis Today, 265, 95-102.

[12] Hu S., He L., Wang Y., Su S., Jiang L., Chen Q., Liu Q., Chi H., Xiang J., Sun L. (2016). Effects of oxygen species from $\mathrm{Fe}$ addition on promoting steam reforming of toluene over $\mathrm{Fe}-\mathrm{Ni} / \mathrm{Al}_{2} \mathrm{O}_{3}$ catalysts. International Journal of Hydrogen Energy, 41, 17967-17975.

[13] Xing R., Dagle V. L., Flake M., Kovarik L., Albrecht K. O., Deshmane C., Dagle R. A. (2016). Steam reforming of fast pyrolysis-derived aqueous phase oxygenates over $\mathrm{Co}, \mathrm{Ni}$, and $\mathrm{Rh}$ metals supported on $\mathrm{MgAl}_{2} \mathrm{O}_{4}$. Catalysis Today, 269, 166-174.

[14] He L., Hu S., Jiang L., Liao G., Chen X., Han H., Xiao L., Ren Q., Wang Y., Su S., Xiang J. (2018). Carbon nanotubes formation and its influence on steam reforming of toluene over $\mathrm{Ni} / \mathrm{Al}_{2} \mathrm{O}_{3}$ catalysts: Roles of catalyst supports. Fuel Processing Technology, 176, 7-14.

[15] Augusto B. L., Ribeiro M. C., Aires F. J. C. S., da Silva V. T., Noronha F. B. (2018). Hydrogen production by the steam reforming of ethanol over cobalt catalysts supported on different carbon nanostructures. Catalysis Today.

[16] Veiga S., Bussi J. (2017). Steam reforming of crude glycerol over nickel supported on activated carbon. Energy Conversion and Management, 141, 79-84.

[17] Liu X., Yang X., Liu C., Chen P., Yue X., Zhang S. (2016). Low-temperature catalytic steam reforming of toluene over activated carbon supported nickel catalysts. Journal of the Taiwan Institute of Chemical Engineers, 65, 233241.

[18] Ng C. A., Wong L. Y., Bashir M. J. K., Ng S. L. (2018). Development of hybrid polymeric polyerthersulfone (PES) membrane incorporated with powdered activated carbon (PAC) for palm oil mill effluent (POME) treatment. International Journal of Integrated Engineering, 10, 137-141.

[19] Daud Z., Ahmad B., Awang H., Abubakar M. H., Ridzuan M. B., Tajarudin H. A. (2018). Removal of COD using delonix regia pods activated carbon adsorbent for natural rubber wastewater treatment. International Journal of Integrated Engineering, 10, 77-83.

[20] Shen C., Zhou W., Yu H., Du L. (2018). Ni nanoparticles supported on carbon as efficient catalysts for steam reforming of toluene (model tar). Chinese Journal of Chemical Engineering, 26, 322-329. 
[21] Bhandari P. N., Kumar A., Bellmer D. D., Huhnke R. L. (2014). Synthesis and evaluation of biochar-derived catalysts for removal of toluene (model tar) from biomass-generated producer gas. Renewable Energy, 66, 346353.

[22] Zhang Y., Lei H., Yang Z., Duan D., Villota E., Ruan R. (2018). From glucose-based carbohydrates to phenol-rich bio-oils integrated with syngas production via catalytic pyrolysis over an activated carbon catalyst. Green Chemistry, 20, 3346-3358.

[23] Yadav B. R., Garg A. (2016). Catalytic oxidation of pulping effluent by activated carbon-supported heterogeneous catalysts. Environmental Technology, 37, 1018-1025.

[24] Jahromi F. G., Ghahreman A. (2019). Effect of surface modification with different acids on the functional groups of AF5 catalyst and its catalytic effect on the atmospheric leaching of enargite. Colloids and Interfaces, 3, 45-61.

[25] ShamsiJazeyi H., Kaghazchi T. (2010). Investigation of nitric acid treatment of activated carbon for enhanced aqueous mercury removal. Journal of Industrial and Engineering Chemistry, 16, 852-858.

[26] Chen Y., Lu W., Guo Y., Zhu Y., Lu H., Song Y. (2018). Synthesis, characterization and photocatalytic activity of nanocrystalline first transition-metal ( $\mathrm{Ti}, \mathrm{Mn}, \mathrm{Co}, \mathrm{Ni}$ and $\mathrm{Zn}$ ) oxisde nanofibers by electrospinning. Applied Sciences, 9, 8-24.

[27] Sing K. S. W. (1985). Reporting physisorption data for gas/solid systems with special reference to the determination of surface area and porosity (Recommendations 1984). Pure and Applied Chemistry, 57, 603-619.

[28] Saleh T. A., Danmaliki G. I. (2016). Influence of acidic and basic treatments of activated carbon derived from waste rubber tires on adsorptive desulfurization of thiophenes. Journal of the Taiwan Institute of Chemical Engineers, 60, 460-468.

[29] Cui B., Zhang J., Liu S., Liu X., Xiang W., Liu L., Xin H., Lefler M. J., Licht S. (2017). Electrochemical synthesis of ammonia directly from $\mathrm{N}_{2}$ and water over iron-based catalysts supported on activated carbon. Green Chemistry, 19, 298-304.

[30] Guan Q., Chen S., Chen Y., Gu J., Li B., Miao R., Chen Q., Ning P. (2017). High performance noble-metal-free $\mathrm{NiCo} / \mathrm{AC}$ bimetal for gasification in supercritical water. International Journal of Hydrogen Energy, 42, 65116518.

[31] Chen X., Carabineiro S. A. C., Bastos S. S. T., Tavares P. B., Órfão J. J. M., Pereira M. F. R., Figueiredo J. L. (2013). Exotemplated copper, cobalt, iron, lanthanum and nickel oxides for catalytic oxidation of ethyl acetate. Journal of Environmental Chemical Engineering, 1, 795-804.

[32] Lankitsi J. Malobela J. H., Willem G. Augustyn, Leskey M. Cele (2014). Nickel-cobalt on carbonaceous supports for the selective catalytic hydrogenation of cinnamaldehyde. Industrial \& Engineering Chemistry Research, 53, 13910-13919.

[33] Jabbour K., Massiani P., Davidson A., Casale S., El Hassan N. (2017). Ordered mesoporous “one-pot” synthesized $\mathrm{Ni}-\mathrm{Mg}(\mathrm{Ca})-\mathrm{Al}_{2} \mathrm{O}_{3}$ as effective and remarkably stable catalysts for combined steam and dry reforming of methane (CSDRM). Applied Catalysis B: Environmental, 201, 527-542.

[34] Yang W., Liu H., Li Y., Wu H., He D. (2016). CO 2 reforming of methane to syngas over highly-stable Ni/SBA-15 catalysts prepared by P123-assisted method. International Journal of Hydrogen Energy, 41, 1513-1523.

[35] Quitete C. P. B., Manfro R. L., Souza M. M. V. M. (2017). Perovskite-based catalysts for tar removal by steam reforming: Effect of the presence of hydrogen sulfide. International Journal of Hydrogen Energy, 42, 9873-9880.

[36] Gao N., Han Y., Quan C. (2018). Study on steam reforming of coal tar over NiCo/ceramic foam catalyst for hydrogen production: Effect of Ni/Co ratio. International Journal of Hydrogen Energy, 43, 22170-22186.

[37] Li Z., Li M., Ashok J., Kawi S. (2019). NiCo@NiCo phyllosilicate@ $\mathrm{CeO}_{2}$ hollow core shell catalysts for steam reforming of toluene as biomass tar model compound. Energy Conversion and Management, 180, 822-830.

[38] Cao J.-P., Ren J., Zhao X.-Y., Wei X.-Y., Takarada T. (2018). Effect of atmosphere on carbon deposition of $\mathrm{Ni} / \mathrm{Al}_{2} \mathrm{O}_{3}$ and $\mathrm{Ni}$-loaded on lignite char during reforming of toluene as a biomass tar model compound. Fuel, 217, 515-521.

[39] Zhang Z., Liu L., Shen B., Wu C. (2018). Preparation, modification and development of Ni-based catalysts for catalytic reforming of tar produced from biomass gasification. Renewable and Sustainable Energy Reviews, 94, 1086-1109.

[40] Bao X., Kong M., Lu W., Fei J., Zheng X. (2014). Performance of $\mathrm{Co} / \mathrm{MgO}$ catalyst for $\mathrm{CO}_{2}$ reforming of toluene as a model compound of tar derived from biomass gasification. Journal of Energy Chemistry, 23, 795-800.

[41] de Castro T. P., Silveira E. B., Rabelo-Neto R. C., Borges L. E. P., Noronha F. B. (2018). Study of the performance of $\mathrm{Pt} / \mathrm{Al}_{2} \mathrm{O}_{3}$ and $\mathrm{Pt} / \mathrm{CeO}_{2} / \mathrm{Al}_{2} \mathrm{O}_{3}$ catalysts for steam reforming of toluene, methane and mixtures. Catalysis Today, 299, 251-262.

[42] de Castro T. P., Peguin R. P. S., Neto R. C. R., Borges L. E. P., Noronha F. B. (2015). Steam reforming of toluene over $\mathrm{Pt} / \mathrm{Ce}_{\mathrm{x}} \mathrm{Zr}_{1-\mathrm{x}} \mathrm{O}_{2} / \mathrm{Al}_{2} \mathrm{O}_{3}$ catalysts. Topics in Catalysis, 59, 292-302.

[43] Silveira E. B., Rabelo-Neto R. C., Noronha F. B. (2017). Steam reforming of toluene, methane and mixtures over $\mathrm{Ni} / \mathrm{ZrO}_{2}$ catalysts. Catalysis Today, 289, 289-301. 